\title{
Recent Developments in the Suzuki-Miyaura Reaction Using Nitroarenes as Electrophilic Coupling Reagents
}

\author{
Lou Rocard and Piétrick Hudhomme* \\ Laboratoire MOLTECH-Anjou, CNRS UMR 6200, UNIV Angers, 2 Bd Lavoisier, 49045 Angers CEDEX, France; \\ lou.rocard@univ-angers.fr \\ * Correspondence: pietrick.hudhomme@univ-angers.fr
}

Received: 29 January 2019; Accepted: 13 February 2019; Published: 26 February 2019

check for updates

\begin{abstract}
Palladium-catalyzed cross-coupling reactions are nowadays essential in organic synthesis for the construction of C-C, C-N, C-O, and other C-heteroatom bonds. The 2010 Nobel Prize in Chemistry to Richard F. Heck, Ei-ichi Negishi, and Akira Suzuki was awarded for the discovery of these reactions. These great advances for organic chemists stimulated intense research efforts worldwide dedicated to studying these reactions. Among them, the Suzuki-Miyaura coupling (SMC) reaction, which usually involves an organoboron reagent and an organic halide or triflate in the presence of a base and a palladium catalyst, has become, in the last few decades, one of the most popular tools for the creation of $\mathrm{C}-\mathrm{C}$ bonds. In this review, we present recent progress concerning the $\mathrm{SMC}$ reaction with the original use of nitroarenes as electrophilic coupling partners reacting with the organoboron reagent.
\end{abstract}

Keywords: Suzuki-Miyaura; nitroarene; palladium-catalyzed cross-coupling

\section{Introduction}

The importance of creating carbon-carbon $(\mathrm{C}-\mathrm{C})$ bonds in organic synthesis is demonstrated by the history of awardees of the Nobel Prize in Chemistry, for example, the Grignard reaction (1912), the Diels-Alder reaction (1950), the Wittig reaction (1979), and the olefin metathesis to Y. Chauvin, R. H. Grubbs, and R. R. Schrock (2005). In the last few decades, transition metals have shown their ability to catalyze the formation of $\mathrm{C}-\mathrm{C}$ single bonds and, among them, palladium-catalyzed reactions have been rapidly shown to be very efficient in organic chemistry [1]. This was demonstrated by the 2010 Nobel Prize in Chemistry, awarded to R. F. Heck, E. Negishi, and A. Suzuki for the formation of a $\mathrm{C}-\mathrm{C}$ single bond through palladium-catalyzed cross-coupling reactions [2]. Among the different metal-catalyzed cross-coupling reactions, the Suzuki-Miyaura coupling (SMC) reaction rapidly became one of the most efficient processes for the construction of $\mathrm{C}-\mathrm{C}$ bonds, due to its high versatility, efficiency, and non-toxicity, making it suitable for industry [3]. This cross-coupling is conventionally performed using organic halide or triflate as an electrophilic partner, and an organoboron reagent as the nucleophile. Very recently, nitroarenes have been reported as new electrophilic counterparts and, in this review, we highlight these new developments around the SMC reaction.

\section{Discussion}

Forty years ago, Suzuki and colleagues reported, in 1979, that organoboron compounds such as 1-alkenylboranes in the presence of a base can be used as coupling partners in palladium-catalyzed cross-coupling with 1-alkenyl, 1-alkynyl or 1-aryl halides [4,5]. The scope of this reaction was further extended to varied aryl, benzyl, alkyl, alkenyl, and alkynyl halides [6-8], as well as triflates [9] 
or nosylates $[10,11]$ as substrates for the oxidative addition of palladium( 0$)$, or, in a few examples, of nickel(0) complex [12,13] (Scheme 1). The oxidative addition corresponding to the first step of the catalytic cycle is often the rate-determining step, and the relative reactivity decreases in the order I > $\mathrm{OTf}>\mathrm{Br}>\mathrm{Cl}$.

$$
\begin{aligned}
& \mathrm{R}-\mathrm{B}\left(\mathrm{OR}^{\prime \prime}\right)_{2}+\mathrm{R}^{\prime}-\mathrm{X} \stackrel{\text { Pd catalyst }}{\text { base }} \underset{\mathrm{R}-\mathrm{R}^{\prime}}{\mathrm{R}} \\
& \mathrm{R}, \mathrm{R}^{\prime}=\text { aryl, alkyl, alkenyl, alkynyl } \\
& \mathrm{X}=\text { halide, triflate ... with } \mathrm{I}>\mathrm{OTf}>\mathrm{Br}>>\mathrm{Cl} \\
& \mathrm{R}^{\prime \prime}=\mathrm{H} \text {, alkyl }
\end{aligned}
$$

Scheme 1. General reaction for the Suzuki-Miyaura palladium-catalyzed cross-coupling reaction.

The organoboron reagent typically used is a boronic acid or a boronic ester for which the use of a base activation facilitates the transfer of the organic group from boron to palladium (transmetallation). Thanks to extensive and recent developments, the SMC reaction is now compatible for all kinds of C-B bonds, and alkyl, aryl, alkenyl and alkynylboronic acids or esters are able to participate as nucleophile partners in the palladium-catalyzed cross-coupling reaction $[7,14]$. Consequently, the stability and weak nucleophilic nature of organoboron compounds have made this reaction very practical, thanks to its wide tolerance of functional groups and its high chemo-, regio- and stereoselectivity. Furthermore, boron compounds are generally non-toxic, and the reaction can be run under very mild conditions.

As the SMC reaction is a popular method to form aryl-aryl bonds, this review highlights recent investigations that have been conducted towards nitroarenes. Nitroarenes are accessible building blocks via nitration of parent arenes that use fuming $\mathrm{HNO}_{3}$ or a mixture of $\mathrm{HNO}_{3}$ and $\mathrm{H}_{2} \mathrm{SO}_{4}$. In comparison to halogenation, as halogens are classical leaving groups in the SMC reaction, mononitration is often more selective because the electron-withdrawing nitro group sufficiently deactivates the second electrophilic substitution [15]. Furthermore, a significant number of aryl halides employed in the SMC reaction are prepared from corresponding nitroarenes, after the reduction of the nitro group and subsequent Sandmeyer halogenation. The direct use of nitroarene is of particular interest because it could reduce the number of steps and cost of synthesis, due to the concomitant advantages of the nitro group, that allow for an interesting and better atom economy process compared to the bromo, iodo, or triflate groups.

Over the last few decades, very few papers have reported on the use of nitroarenes in transition metal cross-couplings [16-18]. Notably, Pd-catalyzed couplings were developed for the construction of C-heteroatom bonds, in particular, for the formation of C-O and C-N bonds [19]. The first example was reported by R. Tamura and L. S. Hegedus in 1982, who described the use of allylic nitro compounds as substrates for $\operatorname{Pd}(0)$-allylic amination [20]. However, it was only very recently, in 2017, that the $\mathrm{C}\left(\mathrm{sp}^{2}\right)-\mathrm{NO}_{2}$ bond was recognized as an electrophilic partner in Pd-catalyzed coupling, in which nitroarene could react with a $\operatorname{Pd}(0)$ catalyst to form $\eta^{2}$-arene palladium complex I (Figure 1 ). The further oxidative addition of the latter afforded complex II, which could subsequently react with a nucleophilic partner, such as amine undergoing Buchwald-Hartwig amination [21], or phenolate for O-arylation (Scheme 2) [22]. Notably, the catalytic amination of nitroarene was facilitated by the use of the catalytic system derived from the bulky biarylphosphine ligand, BrettPhos. The importance of a similar ligand, $t$ Bu-BrettPhos, was also highlighted in Pd-catalyzed nitration of aryl chlorides, triflates or nonaflates. First reported in 2009, this reaction occurs by transmetallation of the $\operatorname{Pd}(\mathrm{II})$ species formed after oxidative addition with $\mathrm{Ar}-\mathrm{X}$ in the catalytic process in the presence of sodium nitrite, followed by reductive elimination to afford nitroarene derivatives (Scheme 2) [23]. 


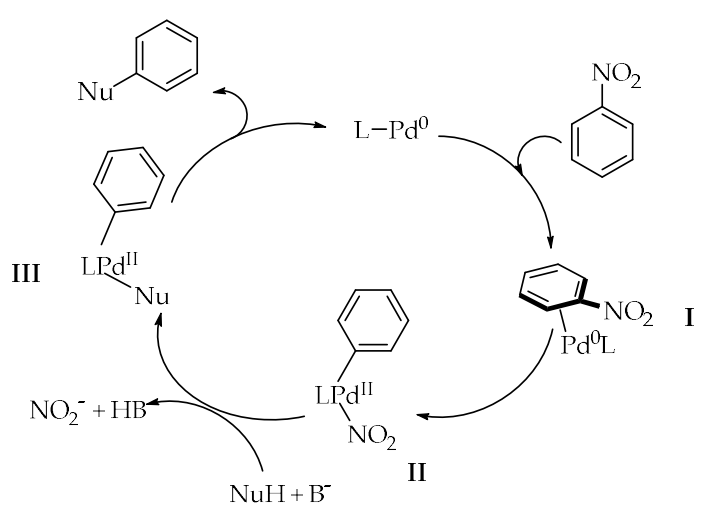

Figure 1. General plausible catalytic cycle for Pd-catalyzed $\mathrm{Nu}-\mathrm{C}$ bond formation using nitroarenes.

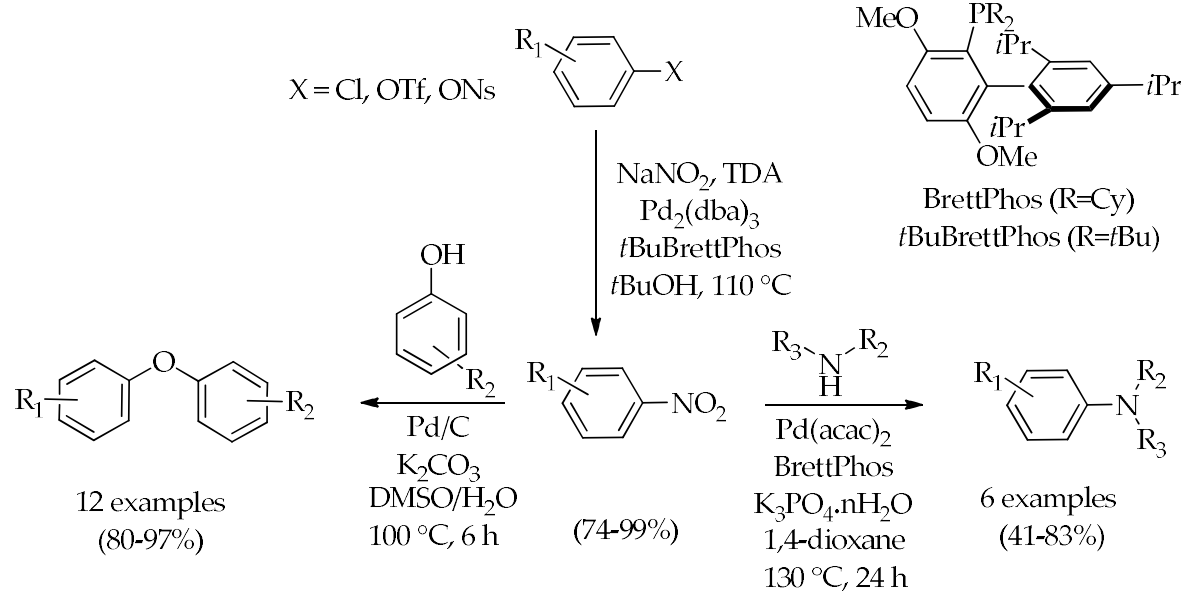

Scheme 2. Pd-catalyzed conversion of aryl chlorides, triflates, and nonaflates into nitroarenes [23], followed by Buchwald-Hartwig amination [21] or Pd-catalyzed O-arylation [22].

Since the nitro group could be involved in the Pd-catalytic cycle, either as an electrophilic partner allowing oxidative addition, or as a nucleophile transmetallating with further reductive elimination, the utilization of nitroarenes in the SMC reaction has recently been investigated. In 2017, Y. Nakao, S. Sakaki, and colleagues reported, for the first time, the use of nitroarenes in the SMC reaction, greatly expanding the scope of the reaction [24]. The reaction was performed with a large range of nitroarenes and boronic acids (electron-rich, electron-poor, sterically hindered, 38 examples, yield $41 \%-84 \%$, Scheme 3). Using optimized conditions, for most of the substrates, the coupling was performed in the presence of $\mathrm{Pd}(\mathrm{acac})_{2}$, BrettPhos, 18-crown-6, and $\mathrm{K}_{3} \mathrm{PO}_{4} \cdot \mathrm{nH}_{2} \mathrm{O}$ in 1,4-dioxane at $130{ }^{\circ} \mathrm{C}$. It is notable that the choice of the ligand appeared to be crucial for the reaction. For instance, to obtain 4-methoxybiphenyl, phosphine-based ligands SPhos, RuPhos, $\mathrm{PCy}_{3}, \mathrm{P}(t \mathrm{Bu})_{3}$, or carbene ligand $\mathrm{IPr}$ were found to be ineffective (around 5\% yield). The use of $\mathrm{Pd}\left(\mathrm{PPh}_{3}\right)_{4}$ as a catalyst was also ineffective. Additionally, the water contamination from the base seemed important for the reaction to occur. 


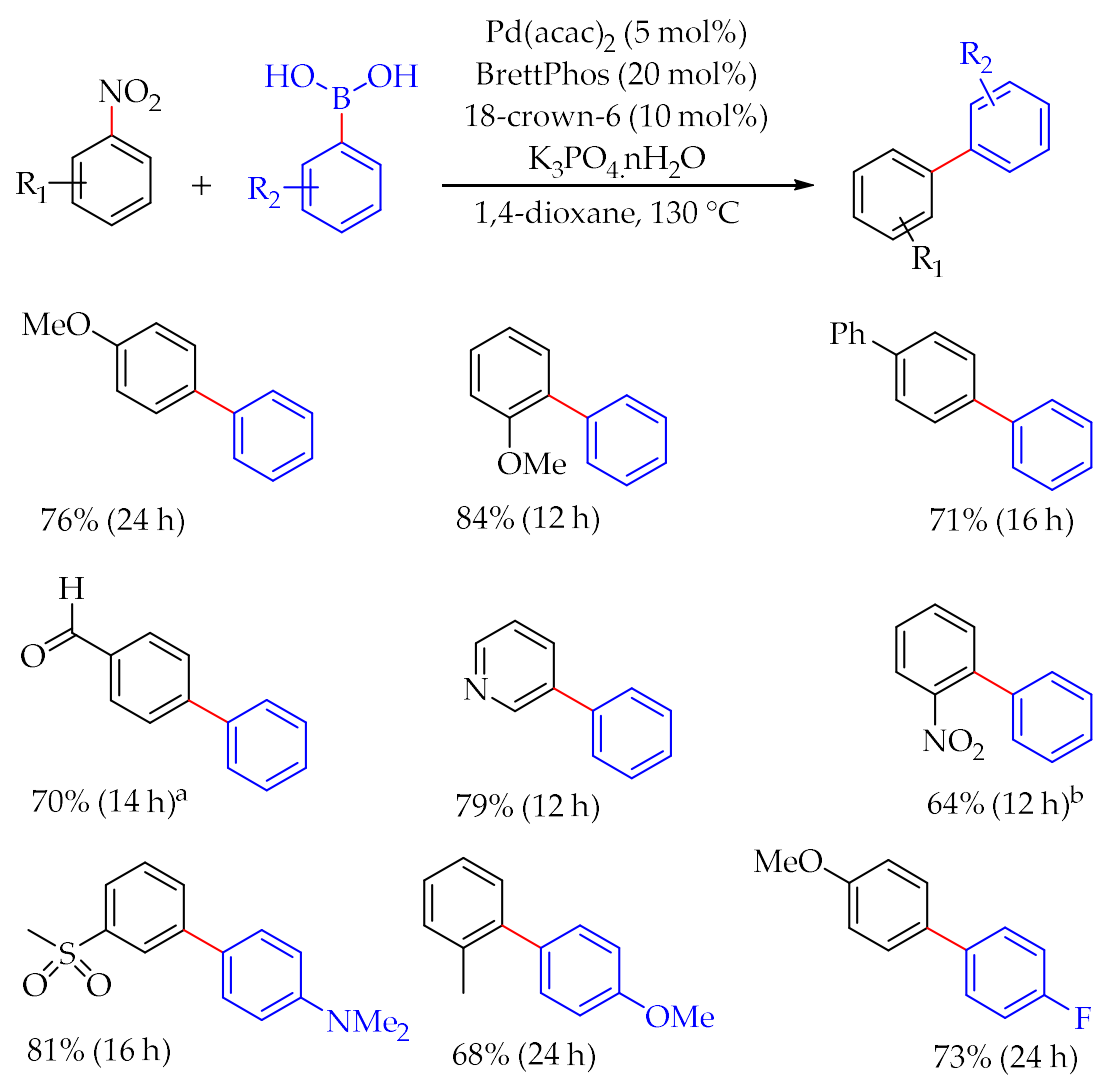

Scheme 3. The Suzuki-Miyaura coupling (SMC) of nitroarenes with various substrates ( ${ }^{\text {a }}$ Isolated yield after hydrolysis of the corresponding acetals. ${ }^{b}$ Reaction with CsF) [24].

The investigations of the mechanistic pathway supported the formation of the $\eta^{2}$-arene palladium complex followed by the cleavage of $\mathrm{C}\left(\mathrm{sp}^{2}\right)-\mathrm{NO}_{2}$ bond via oxidative addition onto the $\mathrm{Pd}(0)$ center (Figure 2). Indeed, the stoichiometric reaction of (cod) $\mathrm{Pd}-\left(\mathrm{CH}_{2} \mathrm{SiMe}_{3}\right)_{2}(\mathrm{cod}=1,5$-cyclooctadienyl) and BrettPhos with nitrobenzene at $60^{\circ} \mathrm{C}$ gave BrettPhos- $\mathrm{Pd}(\mathrm{Ph})\left(\mathrm{NO}_{2}\right)$. The molecular structure of this complex was determined by single-crystal $\mathrm{X}$-ray diffraction with the Pd center coordinated to both phosphorous and the triisopropylphenyl ring of BrettPhos (Figure 3). On the other hand, the reaction with 1-nitronaphtalene at $25^{\circ} \mathrm{C}$ afforded the isolable $\eta^{2}$-arene complex whose structure was confirmed by single-crystal $\mathrm{X}$-ray diffraction, thus proving that the $\eta^{2}$-complex is present in the catalytic cycle. After the formation of the nitroarene-Pd complex, the occurrence of transmetallation between the nitro group and the aryl boron derivative followed by reductive elimination, afforded the biaryl compound. The authors showed that these two steps can occur at $25^{\circ} \mathrm{C}$ in the presence of the base, or at $60{ }^{\circ} \mathrm{C}$ without base and, consequently, that the oxidative addition is the rate-determining step of the cycle.

Many important questions had to be answered in order to understand this cross-coupling reaction involving nitroarenes: 1) why is the $\mathrm{Ar}-\mathrm{NO}_{2}$ bond more difficult to break than $\mathrm{Ar}-\mathrm{Br}$ ?; 2) why can a usual monodentate ligand not be used?; 3) how does the catalytic system derived from BrettPhos ligand control the coupling? Y. Nakao, S. Sakaki, and colleagues investigated the oxidative addition of nitroarenes to $\mathrm{Pd}^{0}$ (BrettPhos) with theoretical calculations [25]. To answer the first question, the authors compared, by using density functional theory (DFT) methods, the Gibbs activation energy $\left(\Delta G^{\circ} \neq\right)$ and the Gibbs reaction energy $\left(\Delta G^{\circ}\right)$ required for the oxidative addition of 4-nitroanisole and 4-bromoanisole from the $\eta^{2}$-adduct $\left(\mathrm{MeOC}_{6} \mathrm{H}_{4} \mathrm{X}\right) \mathrm{Pd}(\mathrm{BrettPhos})$. It was found that the nitro derivative required much higher activation energy to reach the transition state compared to the bromo analogue $\left(30.3 \mathrm{kcal} \cdot \mathrm{mol}^{-1}\right.$ vs. $\left.16.3 \mathrm{for} \mathrm{R}-\mathrm{Br}\right)$. Furthermore, they also discovered that the complex $\mathrm{Pd}^{\mathrm{II}}(\mathrm{Br})\left(\mathrm{C}_{6} \mathrm{H}_{4} \mathrm{OMe}\right)($ BrettPhos $)\left(\Delta \mathrm{G}_{\mathrm{R}}^{\circ}=-17.9 \mathrm{kcal} \cdot \mathrm{mol}^{-1}\right)$ was more stable than $\mathrm{Pd}^{\mathrm{II}}\left(\mathrm{NO}_{2}\right)\left(\mathrm{C}_{6} \mathrm{H}_{4} \mathrm{OMe}\right)($ BrettPhos $)\left(\Delta \mathrm{G}^{\circ} \mathrm{R}=-2.1 \mathrm{kcal} \cdot \mathrm{mol}^{-1}\right)$. Hence, the oxidative addition 
of nitroarene is more difficult than that of bromoarene, both kinetically and thermodynamically. The difference in activation energies is the result of a large energy of deformation being required in the case of the nitroarene, whereas the stability of the $\mathrm{Pd}^{\mathrm{II}}-\mathrm{Br}$ complex is explained by the $\mathrm{Pd}-\mathrm{Br}$ bond energy being stronger than that of $\mathrm{Pd}-\mathrm{NO}_{2}$.

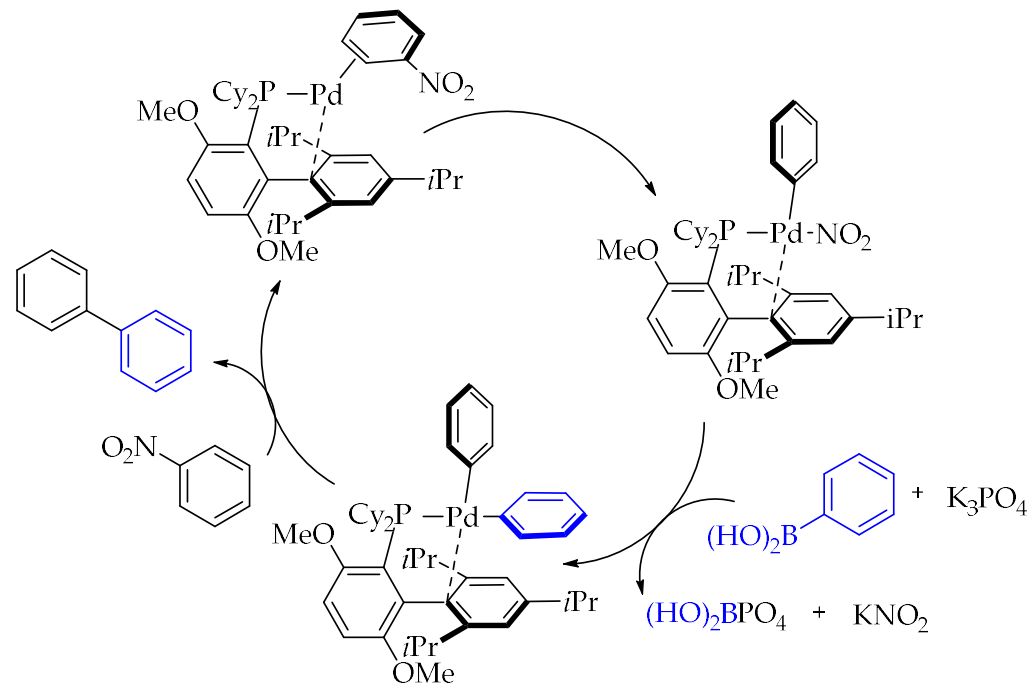

Figure 2. Plausible catalytic cycle for Pd-catalyzed SMC of nitroarenes [24].

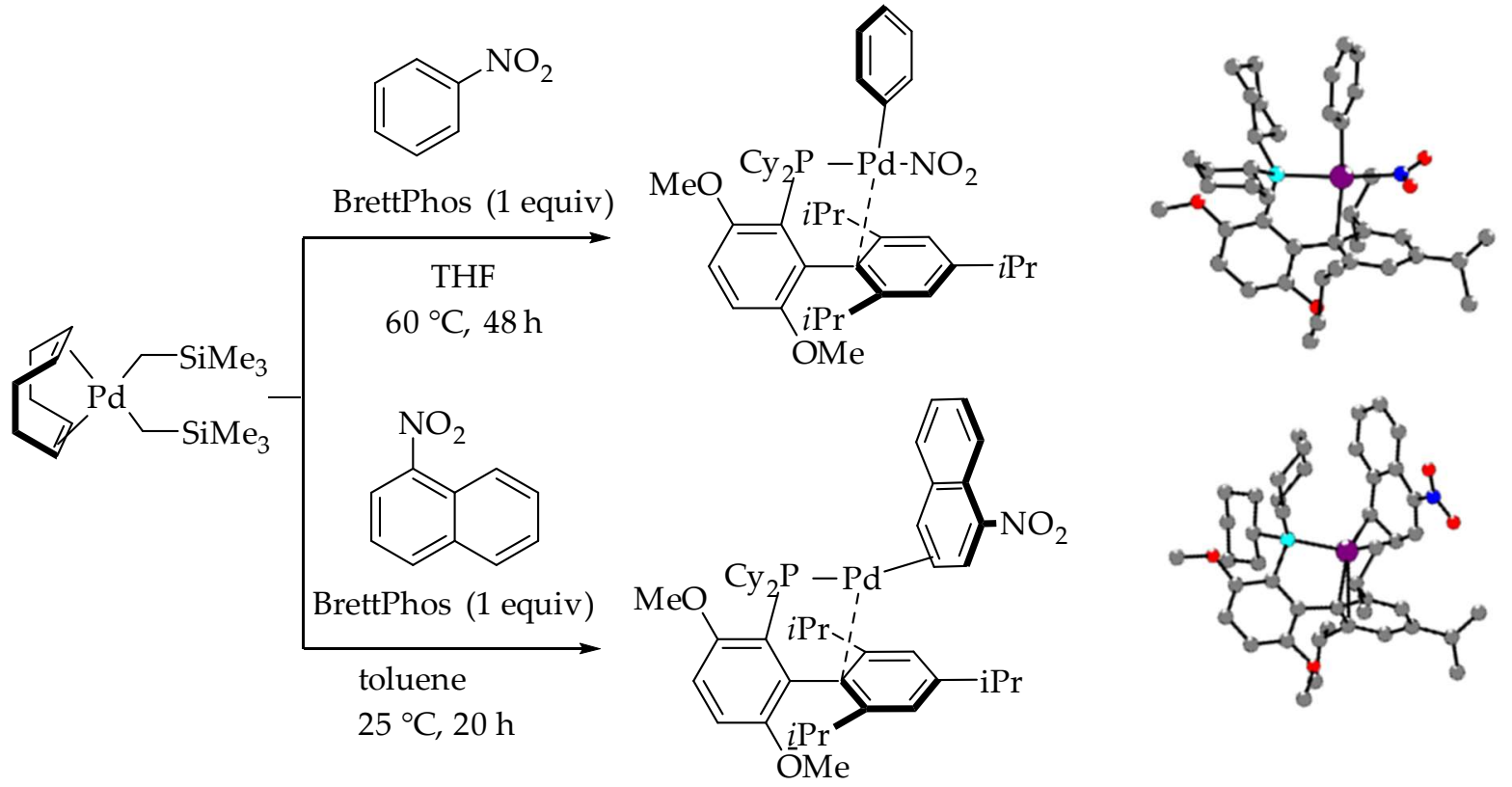

Figure 3. Reaction of Brett-Phos-Pd(0) with nitrobenzene and 1-nitronaphtalene. Crystal structure of Pd-complex obtained by single-crystal $\mathrm{X}$-ray diffraction. Color code: $\mathrm{C}$ in grey, $\mathrm{O}$ in red, $\mathrm{N}$ in blue, $\mathrm{P}$ in cyan, Pd in purple [24].

The role of the bulky biarylphosphine ligand was clarified by comparing the values of $\Delta \mathrm{G}^{\circ \neq}$ and $\Delta \mathrm{G}^{\circ} \mathrm{R}$, which were obtained when the oxidative addition of 4-nitroanisole occurred onto the complexes with the BrettPhos and $\mathrm{PPh}_{3}$ ligands. In the case of the usual $\mathrm{PPh}_{3}$ ligands, the activation barrier was determined to be $32.9 \mathrm{kcal} \cdot \mathrm{mol}^{-1}$ while the reaction energy was $6.6 \mathrm{kcal} \cdot \mathrm{mol}^{-1}$, proving that this step is endergonic and needs more energy to occur. Moreover, a side reaction of dissociation between $\mathrm{NO}_{2}$ and $\mathrm{Pd}^{0}\left(\mathrm{PPh}_{3}\right)_{2}$ can happen at a much lower energy level, explaining why the reaction did not succeed. Finally, during the oxidative addition, the charge transfer (CT) which occurred from 
the HOMO of Pd to the LUMO and LUMO+1 of the substrate plays a significant role. The HOMO of $\mathrm{Pd}^{0}$ (BrettPhos), being at a higher energy level than that of $\mathrm{Pd}^{0}\left(\mathrm{PPh}_{3}\right)_{2}$, is more reactive for the oxidative addition of nitroarene, due to sufficient $\mathrm{CT}$ interaction. Interestingly, the authors predicted that $\mathrm{Pd}^{0}\left(\right.$ BrettPhos- $\left.\mathrm{NMe}_{2}\right)$ should better catalyze the $\mathrm{SMC}$ with nitroarenes because of its higher energy HOMO compared to that of BrettPhos. Last but not least, the authors also theoretically clarified why during the Pd-catalyzed nitration, reported in Scheme 2, a bulkier ligand $t$ Bu-BrettPhos was used. The steric repulsion between the $t \mathrm{Bu}$ groups and the aryl group of the substrate favored the reductive elimination, but not the oxidative addition. This was supported by a positive value of $\Delta \mathrm{G}_{\mathrm{R}}^{\circ}(5.8$ $\left.\mathrm{kcal} \cdot \mathrm{mol}^{-1}\right)$ when the oxidative addition of 4-nitroanisole occurred onto $\mathrm{Pd}^{0}(t \mathrm{Bu}-\mathrm{BrettPhos})$.

In our group, we recently applied the SMC reaction onto nitro-perylenediimide (PDI- $\left.\mathrm{NO}_{2}\right)$ [26]. PDI derivatives are still of particular interest since they are among the most important n-type semiconductors, and are recognized as promising non-fullerene acceptors for organic solar cells [27-30]. All the reported cross-coupling reactions in the PDI series use 1-bromoPDI derivatives. However, the monobromination of PDI is poorly selective, affording a complicated mixture of unreacted PDI, mono-, and bis-bromo-PDI and thus requiring fastidious chromatography for purification [31]. On the other hand, nitration is almost quantitative and 1-nitroPDI can be purified by simple crystallization. To achieve functionalization of PDI- $\mathrm{NO}_{2}$, the SMC reaction with 3-formylphenylboronic acid was carried out in the presence of $\mathrm{Pd}\left(\mathrm{PPh}_{3}\right)_{4}$ and anhydrous $\mathrm{K}_{3} \mathrm{PO}_{4}$ in refluxing THF, and the product was isolated in a satisfactory $81 \%$ yield. In order to investigate the electronic effect of the substituent on the organoboron reagent, the reaction was also performed with 4-formylphenylboronic acid and (4-diphenylamino)phenylboronic acid, affording the corresponding products in $85 \%$ and $75 \%$ yields, respectively (Scheme 4). It is noteworthy that (4-diphenylamino)PDI was previously synthesized in $49 \%$ yield from 1-bromoPDI derivative using SMC [32]. Hence, the reaction appears to be very efficient, with both electron-withdrawing and -donating groups, which highlights the versatility of the method. Interestingly, the coupling in this case was highly efficient, using easily accessible $\mathrm{Pd}\left(\mathrm{PPh}_{3}\right)_{4}$ and showing that the oxidative addition of nitro-PDI is easier than that of nitroarenes, as previously described in this review.

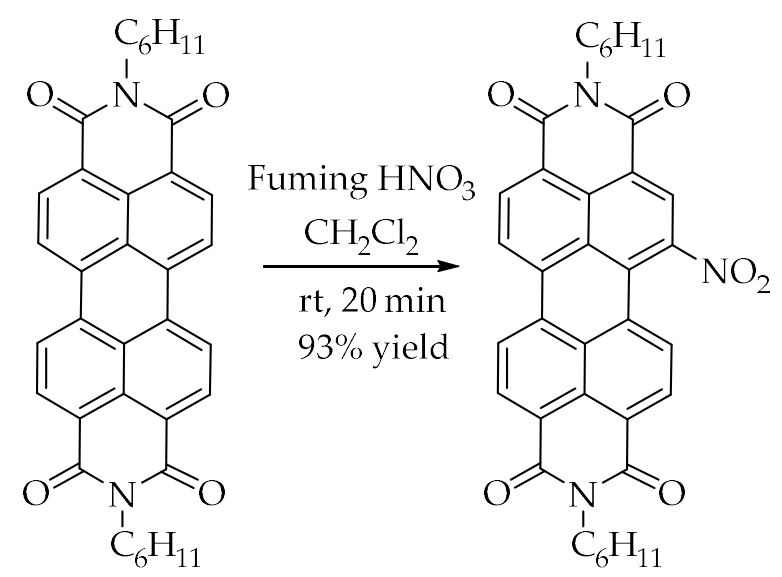<smiles>[R]c1ccc(B(O)c2ccc([R])cc2)cc1</smiles>

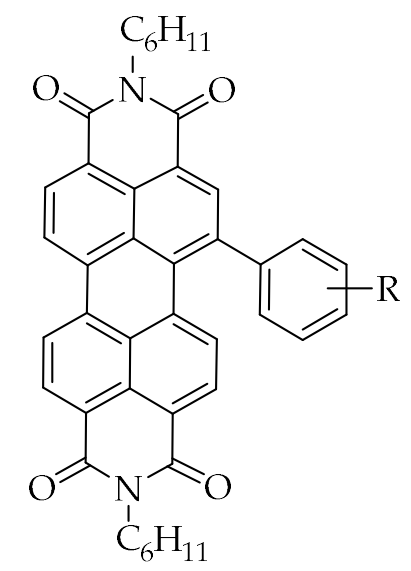

$$
\begin{aligned}
& \mathrm{R}=p-\mathrm{CHO}: 85 \% \text { yield } \\
& \mathrm{R}=m-\mathrm{CHO}: 81 \% \text { yield } \\
& \mathrm{R}=p-\mathrm{Ph}_{2} \mathrm{~N}-: 75 \% \text { yield }
\end{aligned}
$$

Scheme 4. SMC between nitro-perylenediimide (PDI-NO $)_{2}$ and boronic acids bearing electronwithdrawing or -donating groups [25].

\section{Conclusions}

In conclusion, possible alternatives to the use of halogens or triflates as electrophilic reagents in organometallic chemistry are desirable in order to reduce the number of steps, the cost of synthesis 
and, eventually, the atom economy. In this respect, the recent discoveries of palladium-catalyzed Suzuki-Miyaura cross-coupling using nitroarenes have opened new horizons in this field, highlighting nitroarenes as suitable electrophilic counterparts of boronic acids or boronic esters. Nitroarenes are well-tolerated in classical Suzuki-Miyaura coupling, but this reaction seems to be more difficult than that using halogenated analogues, and requires a bulky biarylphosphine ligand. However, the promising coupling between electron-deficient 1-nitroperylenediimide $\left(\mathrm{PDI}-\mathrm{NO}_{2}\right)$ and arylboronic acids can occur using a classical $\mathrm{Pd}\left(\mathrm{PPh}_{3}\right)_{4}$ catalyst. Until now, the use of nitroarenes in palladium-catalyzed cross-coupling remains poorly explored, but further developments are expected in the near future in order to extend its scope. In particular, this extension of the Suzuki-Miyaura reaction using nitroarenes could find nice applications in the synthesis of important chemicals for pharmaceuticals or varied organic materials.

Funding: This research received no external funding.

Conflicts of Interest: The authors declare no conflict of interest.

\section{Abbreviations of Ligands}

Brett Phos (2-(Dicyclohexylphosphino)3,6-dimethoxy-2' $4^{\prime}, 6^{\prime}$-triisopropyl-1,1'-biphenyl)

SPhos (2-Dicyclohexylphosphino-2', $6^{\prime}$-dimethoxybiphenyl)

RuPhos (2-Dicyclohexylphosphino-2', $6^{\prime}$-diisopropoxybiphenyl)

$\mathrm{PCy}_{3} \quad$ (Tricyclohexylphosphine)

IPr (1,3-bis(2,6-diisopropylphenyl)imidazol-2-ylidene)

\section{References}

1. Johansson Seechurn, C.C.C.; Kitching, M.O.; Colacot, T.J.; Snieckus, V. Palladium-Catalyzed Cross-Coupling: A Historical Contextual Perspective to the 2010 Nobel Prize. Angew. Chem. Int. Ed. 2012, 51, 5062-5085. [CrossRef] [PubMed]

2. Suzuki, A. Cross-Coupling Reactions of Organoboranes: An Easy Way to Construct C-C Bonds (Nobel Lecture). Angew. Chem. Int. Ed. 2011, 50, 6722-6737. [CrossRef] [PubMed]

3. Miyaura, N.; Suzuki, A. Palladium-Catalyzed Cross-Coupling Reactions of Organoboron Compounds. Chem. Rev. 1995, 95, 2457-2483. [CrossRef]

4. Miyaura, N.; Yamada, K.; Suzuki, A. A new stereospecific cross-coupling by the palladium-catalyzed reaction of 1-alkenylboranes with 1-alkenyl or 1-alkynyl halides. Tetrahedron Lett. 1979, 3437-3440. [CrossRef]

5. Miyaura, N.; Suzuki, A. Stereoselective synthesis of arylated (E)-alkenes by the reaction of alk-1-enylboranes with aryl halides in the presence of palladium catalyst. J. Chem. Soc. Chem. Commun. 1979, 866-867. [CrossRef]

6. Miyaura, N.; Yanagi, T.; Suzuki, A. The palladium-catalyzed cross-coupling reaction of phenylboronic acid with haloarenes in the presence of bases. Synth. Commun. 1981, 11, 513-519. [CrossRef]

7. Suzuki, A. Recent advances in the cross-coupling reactions of organoboron derivatives with organic electrophiles, 1995-1998. J. Organomet. Chem. 1999, 576, 147-168. [CrossRef]

8. Suzuki, A. Synthetic studies via the cross-coupling reaction of organoboron derivatives with organic halides. Pure Appl. Chem. 1991, 63, 419-422. [CrossRef]

9. Norberg, A.M.; Sanchez, L.; Maleczka, R.E., Jr. Aryl-aryl cross-couplings that avoid the preparation of haloaromatics. Curr. Opin. Drug Discov. Dev. 2008, 11, 853-869.

10. Dikova, A.; Cheval, N.P.; Blanc, A.; Weibel, J.-M.; Pale, P. Aryl and heteroaryl nosylates as stable and cheap partners for Suzuki-Miyaura cross-coupling reactions. Tetrahedron 2016, 72, 1960-1968. [CrossRef]

11. Cheval, N.P.; Dikova, A.; Blanc, A.; Weibel, J.-M.; Pale, P. Vinyl Nosylates: An Ideal Partner for Palladium-Catalyzed Cross-Coupling Reactions. Chem. Eur. J. 2013, 19, 8765-8768. [CrossRef] [PubMed]

12. Han, F.-S. Transition-metal-catalyzed Suzuki-Miyaura cross-coupling reactions: A remarkable advance from palladium to nickel catalysts. Chem. Soc. Rev. 2013, 42, 5270-5298. [CrossRef] [PubMed]

13. Payard, P.-A.; Perego, L.A.; Ciofini, I.; Grimaud, L. Taming Nickel-Catalyzed Suzuki-Miyaura Coupling: A Mechanistic Focus on Boron-to-Nickel Transmetalation. ACS Catal. 2018, 8, 4812-4823. [CrossRef] 
14. Maluenda, I.; Navarro, O. Recent developments in the Suzuki-Miyaura reaction: 2010-2014. Molecules 2015, 20, 7528-7557. [CrossRef] [PubMed]

15. Bradfield, A.E.; Jones, B. Kinetics and mechanism of some electrophilic benzene-substitution reactions. Trans. Faraday Soc. 1941, 37, 726-743. [CrossRef]

16. Zheng, X.-W.; Ding, J.-C.; Chen, J.-X.; Gao, W.-X.; Liu, M.-C.; Wu, H.-Y. The Coupling of Arylboronic Acids with Nitroarenes Catalyzed by Rhodium. Org. Lett. 2011, 13, 1726-1729. [CrossRef] [PubMed]

17. Zhang, J.; Chen, J.; Liu, M.; Zheng, X.; Ding, J.; Wu, H. Ligand-free copper-catalyzed coupling of nitroarenes with arylboronic acids. Green Chem. 2012, 14, 912-916. [CrossRef]

18. Bahekar, S.S.; Sarkate, A.P.; Wadhai, V.M.; Wakte, P.S.; Shinde, D.B. CuI catalyzed CS bond formation by using nitroarenes. Catal. Commun. 2013, 41, 123-125. [CrossRef]

19. Yang, Y. Palladium-Catalyzed Cross-Coupling of Nitroarenes. Angew. Chem. Int. Ed. 2017, 56, 15802-15804. [CrossRef] [PubMed]

20. Tamura, R.; Hegedus, L.S. Palladium(0)-catalyzed allylic alkylation and amination of allylnitroalkanes. J. Am. Chem. Soc. 1982, 104, 3727-3729. [CrossRef]

21. Inoue, F.; Kashihara, M.; Yadav, M.R.; Nakao, Y. Buchwald-Hartwig Amination of Nitroarenes. Angew. Chem. Int. Ed. 2017, 56, 13307-13309. [CrossRef] [PubMed]

22. Begum, T.; Mondal, M.; Borpuzari, M.P.; Kar, R.; Gogoi, P.K.; Bora, U. Palladium-on-Carbon-Catalyzed Coupling of Nitroarenes with Phenol: Biaryl Ether Synthesis and Evidence of an Oxidative-Addition-Promoted Mechanism. Eur. J. Org. Chem. 2017, 2017, 3244-3248. [CrossRef]

23. Fors, B.P.; Buchwald, S.L. Pd-Catalyzed Conversion of Aryl Chlorides, Triflates, and Nonaflates to Nitroaromatics. J. Am. Chem. Soc. 2009, 131, 12898-12899. [CrossRef] [PubMed]

24. Yadav, M.R.; Nagaoka, M.; Kashihara, M.; Zhong, R.-L.; Miyazaki, T.; Sakaki, S.; Nakao, Y. The Suzuki-Miyaura Coupling of Nitroarenes. J. Am. Chem. Soc. 2017, 139, 9423-9426. [CrossRef] [PubMed]

25. Zhong, R.-L.; Nagaoka, M.; Nakao, Y.; Sakaki, S. How to Perform Suzuki-Miyaura Reactions of Nitroarene or Nitrations of Bromoarene Using a Pd0 Phosphine Complex: Theoretical Insight and Prediction. Organometallics 2018, 37, 3480-3487. [CrossRef]

26. El-Berjawi, R.; Hudhomme, P. Synthesis of a perylenediimide-fullerene C60 dyad: A simple use of a nitro leaving group for a Suzuki-Miyaura coupling reaction. Dyes Pigments 2018, 159, 551-556. [CrossRef]

27. Fernández-Lázaro, F.; Zink-Lorre, N.; Sastre-Santos, Á. Perylenediimides as non-fullerene acceptors in bulk-heterojunction solar cells (BHJSCs). J. Mater. Chem. A 2016, 4, 9336-9346. [CrossRef]

28. Venkateswararao, A.; Liu, S.-W.; Wong, K.-T. Organic polymeric and small molecular electron acceptors for organic solar cells. Mater. Sci. Eng. R Rep. 2018, 124. [CrossRef]

29. Wadsworth, A.; Moser, M.; Marks, A.; Little, M.S.; Gasparini, N.; Brabec, C.J.; Baran, D.; McCulloch, I. Critical review of the molecular design progress in non-fullerene electron acceptors towards commercially viable organic solar cells. Chem. Soc. Rev. 2019. [CrossRef] [PubMed]

30. Zhang, J.; Tan, H.S.; Guo, X.; Facchetti, A.; Yan, H. Material insights and challenges for non-fullerene organic solar cells based on small molecular acceptors. Nat. Energy 2018, 3, 720-731. [CrossRef]

31. Liu, Y.; Zhao, J. Visible light-harvesting perylenebisimide-fullerene (C60) dyads with bidirectional "ping-pong" energy transfer as triplet photosensitizers for photooxidation of 1,5-dihydroxynaphthalene. Chem. Commun. 2012, 48, 3751-3753. [CrossRef] [PubMed]

32. Cao, L.; Xu, L.; Zhang, D.; Zhou, Y.; Zheng, Y.; Fu, Q.; Jiang, X.-F.; Lu, F. D-A dyad and D-A-D triad incorporating triphenylamine, benzanthrone and perylene diimide: Synthesis, electrochemical, linear and nonlinear optical properties. Chem. Phys. Lett. 2017, 682, 133-139. [CrossRef]

(C) 2019 by the authors. Licensee MDPI, Basel, Switzerland. This article is an open access article distributed under the terms and conditions of the Creative Commons Attribution (CC BY) license (http://creativecommons.org/licenses/by/4.0/). 